\title{
ANALISIS PERILAKU RETROFIT KOLOM BETON BERKOMPOSISI STEEL FIBER (ENGINEERED CEMENTITIOUS COMPOSITE / ECC) AKIBAT BEBAN AKSIAL DENGAN MENGGUNAKAN SOFTWARE BERBASIS FINITE ELEMENT ANALYSIS
}

\author{
Bagas Rahmanduta Subchan ${ }^{1 *}$, Gati Annisa Hayu ${ }^{2}$, Entin Hidayah ${ }^{2}$ \\ 1 Mahasiswa, Program Studi S-1 Teknik Sipil, Universitas Jember \\ 2 Dosen, Jurusan Teknik Sipil, Universitas Jember \\ *Korespondensi: subchanbagas@gmail.com
}

\begin{abstract}
This study presents a simulation analysis of the non-linear behavior of retrofit concrete material due to uniaxial loads modeled in the form of cylinders measuring $150 \mathrm{~mm}$ in diameter and $200 \mathrm{~mm}$ in depth using the ABAQUS. Analysis of this auxiliary program includes cases of normal concrete retrofit, concrete with retrofit concrete with a composition of $1 \%$ steel fiber, and concrete with retrofit concrete composed of $2 \%$ steel fiber. From the results of the study conducted, it was shown that in modeling the properties of concrete damaged plasticity in ABAQUS, the use of accurate compressive behavior equations for concrete cases with normal concrete retrofit was core concrete and retrofit concrete using the Alfarah, et al equation. For the case of concrete with steel fiber composition retrofit, core concrete uses the Alfarah equation, and retrofit concrete uses Zhou Jiajia, et al. Whereas to model the tensile behavior accurately in the case of concrete with normal concrete retrofit using the Alfarah, et al equation. And the case of concrete with retrofit steel fiber compositions using the CEB-FIB equation and the Ali \& Nehdi equation. The results of ABAQUS analysis of force vs. displacement show a graphical pattern close to the similarity of retrofit concrete column experimental results ECCl error force ratio and displacement $14.86 \%$ and $-10.60 \%$, and ECC2 14.82\% and 8.01). Based on the stress analysis shows that there is a gradual increase in core concrete where the peak of stress is found in the core area of the concrete core and in the retrofit area is divided into two regions, namely stressing on the center and pulling on a small part of upper and lower column retrofit.
\end{abstract}

Keywords: behavior of materials, retrofit, concrete column, finite element analysis

\section{PENDAHULUAN}

Pemahaman mengenai perilaku struktural material pada umumnya diperoleh dari hasil pengujian eksperimental di laboratorium. Uji eksperimental ini termasuk bagian penting dalam penelitian dikarenakan menghasilkan respon struktur dalam keadaan sesungguhnya. Di sisi lain, uji eksperimental memiliki kekurangan yaitu dibutuhkannya data pengujian yang sangat banyak agar mendapatkan hasil eksperimental yang akurat. Sehingga perlakuan ini membutuhkan biaya yang besar dan juga waktu yang panjang. Berangkat pada permasalahan tersebut maka dibutuhkannya suatu alternatif yang dapat memberikan kemudahan dalam pengerjaan yang menghasilkan perilaku struktural pada benda uji. Solusi alternatif tersebut yaitu dengan menggunakan analisa pendekatan simulasi metode numerik yaitu dengan metode elemen hingga atau FEM (Finite Element Method). Pendekatan dengan metode elemen hingga ini telah tersedia pada program bantu 
ABAQUS. Program bantu ABAQUS memiliki kelebihan tidak hanya dapat menganalisa struktur open frame namun juga dapat mengetahui perilaku elemen-elemen dari struktur tersebut. Pendekatan pada program bantu ABAQUS ini sangatlah membantu para engineer dalam merancang, namun dibutuhkan suatu perbandingan keakuratan dari hasil eksperimental maupun hasil analisa program bantu ABAQUS apakah perilaku yang dihasilkan mendekati atau tidaknya. Penelitian ini digunakan perbaikan kolom dengan metode concrete jacketing dengan perbandingan antara hasil uji eksperimental dengan hasil analisa program bantu ABAQUS. Perkuatan kolom menggunakan metode concrete jacketing merupakan solusi alternatif yang efektif dalam meningkatkan kinerja kolom. Konsep metode ini adalah pembesaran dimensi dan penambahan tulangan pada elemen tersebut. Penelitian ini menggunakan data pada hasil eksperimental pada penelitian yang dilakukan oleh Gholampour, A., dkk (2019) yang berjudul "Experimental investigation of the performance of concrete columns strengthened with fiber reinforced concrete jacket" [1].

\section{TINJAUAN PUSTAKA}

\subsection{Perilaku Tekan Beton Normal}

Beton merupakan material yang dapat getas memiliki sifat tegangan dan regangan yang nonlinier. Nonlinier sendiri membuktikan bentuk dan penambahan retakan selama struktur diberi beban. Berbagai persamaan tersedia untuk memperkirakan perilaku nonlinier. Hubungan tegangan regangan beban tekan uniaksial dapat menggunakan persamaan model elastis beton Carreira dan Chu dan persamaan model elastis beton Alfarah, dkk. Persamaan model elastis ini digunakan untuk menghitung kurva tegangan regangan multi linier untuk beton. Persamaan model elastis beton merujuk pada Carreira dan Chu sebagai berikut [2].

$$
\begin{aligned}
& E_{0}=0.0736 w^{1.51}\left(f^{\prime} c\right)^{0.3} \\
& \sigma_{c}=\frac{f^{\prime} c \cdot \beta \cdot\left(\varepsilon_{c} / \varepsilon_{c}\right)}{\beta-1+\left(\varepsilon_{c} / \varepsilon_{c}\right)^{\beta}} \\
& \beta=\left[\frac{f^{\prime} c}{32.4}\right]^{3}+1.55 \\
& d_{c}=1-\frac{\sigma_{c}}{f^{\prime} c}
\end{aligned}
$$

Dimana :

$\sigma \mathrm{c}=$ tegangan pada setiap regangan $\varepsilon, \mathrm{MPa}$

$\varepsilon \mathrm{c}=$ regangan pada tegangan $\sigma \mathrm{c}$

$\varepsilon c^{\prime}=$ regangan pada kuat tekan maksimum f'c

Variabel persamaan Alfarah, dkk [3] dalam mengartikan kuat tekan mengasumsikan dengan variabel fcm yang mengacu pada panduan CEBFIP (MC-2010). Pada panduan CEB-FIP (MC2010) dijelaskan bahwa apabila desain yang digunakan sebagai analisa adalah kelas beton / concrete grade maka fcm harus diasumsikan f'c $+8 \mathrm{MPa}$, sedangkan untuk mutu beton yang sudah diketahui maka menggunakan nilai f'c tersebut. Jadi, persamaan model elastis beton merujuk pada Alfarah, dkk dapat ditunjukkan sebagai berikut. [3] :

$$
\begin{aligned}
E_{0}= & E_{c i}\left(0.8+0.2 \frac{f c m}{88}\right) \\
\sigma_{c(1)}= & E_{0} \varepsilon_{c} \\
\sigma_{c(2)}= & \frac{E_{c i} \frac{\varepsilon_{c}}{f c m}-\left(\frac{\epsilon_{c}}{\varepsilon_{c m}}\right)^{2}}{1+\left(E_{c i} \frac{\ell_{c}}{f c m}-2\right) \frac{\varepsilon_{c}}{\varepsilon_{c m}}} f c m \\
\sigma_{c(3)}= & \left(\frac{2+\gamma_{c} \cdot f c m \cdot \varepsilon_{c m}}{2 \cdot f c m}-\gamma_{c} \cdot \varepsilon_{c}+\right. \\
& \left.\frac{\varepsilon_{c}^{2} \cdot \gamma_{c}}{2 \cdot \varepsilon_{c m}}\right)^{-1}
\end{aligned}
$$

Dimana :

$\mathrm{Ec}=$ modulus elastisitas

Eci $=$ modulus deformasi beton= $\left(10000 .\left(f^{\prime} c\right)^{(1 / 3)}\right)$

$\varepsilon \mathrm{cm}=$ regangan saat tegangan puncak $=0,0022$

$\varepsilon \mathrm{c}=$ regangan saat loading pembebanan

$\mathrm{fcm}=$ tegangan puncak (kuat tekan beton) 


$$
\begin{aligned}
& \gamma_{c}=\frac{\pi^{2} \cdot f c m \cdot \varepsilon_{c m}}{2\left[\frac{G_{c h}}{l e q}-0,5 \cdot f c m\left(\varepsilon_{c m}(1-b)+b \frac{f c m}{E_{0}}\right]^{2}\right.} \\
& \mathrm{G}_{c h}=\left(\frac{f c m}{f t m}\right)^{2} \cdot G f \\
& \mathrm{~b}=0,9
\end{aligned}
$$

Untuk perhitungan parameter kerusakan (damage parameter) menggunakan persamaan berikut :

$$
\begin{aligned}
d_{c}= & 1-\frac{1}{2+a_{c}}\left[2\left(1+a_{c}\right) \exp \left(-b_{c} \varepsilon_{c}^{c h}\right)-\right. \\
& \left.a_{c} \exp \left(-2 b_{c} \varepsilon_{c}^{c h}\right)\right]
\end{aligned}
$$

Dimana :

$a=7.873$

$b=1.97(f c) G$

$l$ leq $=$ ukuran mesh pemodelan $(\mathrm{mm})$

\subsection{Perilaku Tarik Beton Normal}

Hubungan tegangan dan regangan pada perilaku tarik beton diasumsikan tegangan tarik naik secara linier bersamaan dengan regangan tarik hingga mencapai kuat tarik ultimit atau ft. Kemudian tegangan semakin menurun secara linier. Hubungan tegangan regangan beban tarik uniaksial juga dapat menggunakan persamaan model elastis beton Carreira dan Chu, modifikasi persamaan Wahalathantri dan persamaan model elastis beton Alfarah, dkk. Persamaan perilaku tarik beton merujuk pada Carreira dan Chu dan modifikasi persamaan Wahalathantri sebagai berikut. [4,5]

$$
\begin{aligned}
& f_{t}=g_{1} x \sqrt{w \cdot f^{\prime} c} \\
& d_{t}=1-\frac{\partial_{t}}{f t}
\end{aligned}
$$

Dimana :

$\mathrm{ft}=$ tegangan tarik

$\varepsilon \mathrm{t}=$ regangan tarik

$\mathrm{E} 0=$ modulus elastisitas beton

$\mathrm{ft}^{\prime}=$ tegangan tarik maksimum beton

$\varepsilon \mathrm{t}=1 / 10 \times \varepsilon \beta=1,8$

$$
\begin{array}{ccc}
\text { Wahalathantri } & \text { dalam penelitiannya } & b_{t}=\frac{0.453 \cdot f^{\prime} c^{2 / 3}}{G_{f}} \\
\text { mengusulkan model } & \text { modifikasi tegangan } & a=1
\end{array}
$$

regangan tarik beton untuk program bantu Abaqus dapat diilustrasikan pada Gambar 1.

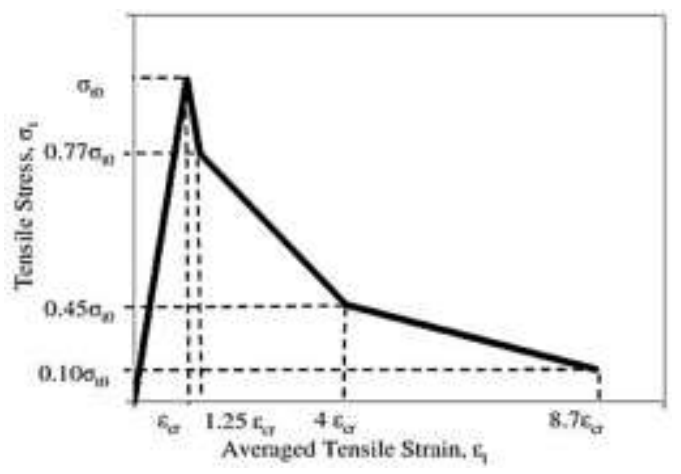

Gambar 1. Perilaku Tarik Beton Merujuk Pada Persamaan Modifikasi Wahalathantri

Sedangkan, persamaan model perilaku tarik beton merujuk pada Alfarah, dkk. sebagai berikut. [3]

$$
\begin{aligned}
& \frac{\sigma_{t}(w)}{f t m}=\left[1+\left(c_{1} \frac{w}{w_{c}}\right)^{3}\right] e^{c_{2} \frac{w}{w_{c}}}-\frac{w}{w_{c}}(1+ \\
& \left.c_{1}^{3}\right) e^{-c_{2}}
\end{aligned}
$$

Dimana :

$\mathrm{ftm}=$ kuat tarik maksimum $=0.3016 \mathrm{fck}^{2 / 3}$

$\mathrm{wc}=$ critical crack opening $=5.14 \mathrm{Gf} / \mathrm{ftm}$

$\mathrm{c} 1=3$

c2 $=6.93$

Perhitungan perilaku tarik merujuk pada persamaan Alfarah, dkk. perlu dicatat bahwa nilai $\sigma \mathrm{t}(0)=\mathrm{ftm}$ dan $\sigma \mathrm{t}(\mathrm{wc})=0$, sehingga didapat kurva perilaku tarik pada beton secara berurutan. Untuk perhitungan parameter kerusakan atau damage parameter menggunakan persamaan sebagai berikut :

$$
\begin{aligned}
d_{t}= & 1-\frac{1}{2+a_{t}}\left[2\left(1+a_{t}\right) \exp \left(-b_{t} \varepsilon_{c}^{c h}\right)-\right. \\
& \left.a_{t} \exp \left(-2 b_{t} \varepsilon_{c}^{c h}\right)\right]
\end{aligned}
$$

Dimana : 
$G=0.073 . f \mathrm{~cm}^{0.18}$

leq $=$ ukuran mesh pemodelan $(\mathrm{mm})$

\subsection{Perilaku Tekan Beton Berkomposisi Steel Fiber}

Perilaku tekan beton berkomposisi steel fiber secara konsep hampir sama dengan beton normal, namun penggunaan persamaan untuk mengilustrasikan beton berbeda. Hubungan tegangan regangan beban tekan uniaksial pada beton berkomposisi steel fiber dapat menggunakan persamaan model beton Zhou Jiajia, dkk dan untuk modulus elastisitasnya menggunakan persamaan yang lebih akurat yaitu persamaan yang diusulkan Zhou Jiajia, dkk. [6]

$$
\begin{aligned}
& E_{0}=1.5 \sqrt[0.63:]{f^{\prime} c} G P a \\
& \sigma=\left\{\begin{array}{cc}
E_{0} \varepsilon & (14) \\
E_{0} \varepsilon \cdot(1-\alpha) & \left(\varepsilon_{0,4}<\varepsilon<\varepsilon_{0,4}\right)
\end{array}\right. \\
& d_{c}=1-\frac{\sigma_{c}}{f^{\prime \prime c}}
\end{aligned}
$$

Dimana :

$$
\alpha=a \cdot \frac{E_{0} \varepsilon}{f c r}-b
$$

$\varepsilon 0,4=$ regangan saat $40 \%$ kuat tekan ultimit

$\mathrm{a}=0,308$

$\mathrm{b}=0,124$

\subsection{Perilaku Tarik Beton Berkomposisi Steel Fiber}

Beton berkomposisi low steel fiber memiliki nilai kuat tarik yang berbeda dengan beton biasa. Untuk nilai kuat tarik maksimum digunakan persamaan CEB-FIB, sedangkan untuk grafik didapatkan melalui persamaan yang diusulkan oleh Ali \& Nehdi. [7,8]

$$
\begin{gathered}
f_{t}=1.4\left(\frac{f^{\prime} c-13}{10}\right)^{2 / 3} \\
d_{t}=1-\frac{d_{t}}{f t} \\
\frac{d_{t}(w)}{f t}=\left[1+\left(c_{1} \frac{w}{w_{c}}\right)^{3}\right] e^{c_{2} \frac{w}{w_{c}}}-\frac{w}{w_{c}}(1+
\end{gathered}
$$

$$
G f=\left(0.0469 d_{i=1}^{2}-0.5 d_{n}+26\right)\left(\frac{f^{t} c}{10}\right)^{0.7}
$$

Dimana :

$\mathrm{ft}=$ tegangan tarik

$\mathrm{fc}=$ tegangan tekan

$\mathrm{wc}=$ critical crack opening $=5.14 \mathrm{Gf} / \mathrm{ft}$

$\mathrm{c} 1=3$

c2 $=6.93$

$\mathrm{Gf}=$ energy fraktur

$\mathrm{da}=$ ukuran agregat maksimum

\subsection{Baja Tulangan}

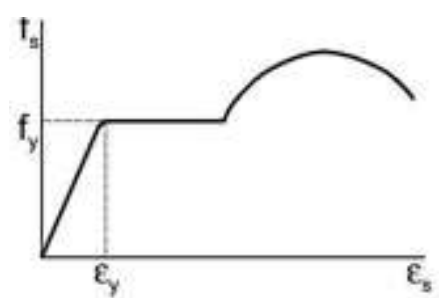

Gambar 2. Grafik Perilaku Tegangan Baja

Perilaku baja tulangan saat diasumsi elastis-plastis terilustrasikan pada Gambar 2. Parameter yang digunakan adalah modulus elastisitas (Es), tegangan leleh (fy), dan rasio Poisson (v). Ikatan beton dan baja tulang pada pemodelan diasumsikan mengikat sempurna.

Sifat baja tulangan menggunakan sifat mengikuti keadaan sebenarnya sifat baja tulangan, sehingga baja tulangan tidak dianggap plastis sempurna tetapi mengalami sifat pengerasan atau steel hardening. Nilai yang dimaksud diperoleh melalui hasil laboratorium tegangan versus regangan pada baja tulangan (sumber : Pacific Steel). Kelas baja tulangan diambil sesuai dengan mutunya yaitu kelas $300 \mathrm{E}$ dengan mutu $320 \mathrm{MPa}$. Hasil tegangan versus regangan baja tulangan tersebut perlu dikonversi dari engineering curve menjadi true curve yang didapat dari persamaan berikut :

$$
\begin{aligned}
& \sigma_{t r u}=\sigma_{\text {nom }}\left(1+\varepsilon_{\text {nom }}\right) \\
& \varepsilon_{t r u}=\ln \left(1+\varepsilon_{\text {nom }}\right) \\
& \varepsilon_{p l}=\varepsilon_{t r u}-\frac{\sigma_{t r u}}{E}
\end{aligned}
$$




\section{METODOLOGI}

\subsection{Studi Kasus}

Elemen struktur yang menjadi bahan adalah menggunakan kolom beton berbentuk silinder dengan ukuran diameter $150 \mathrm{~mm}$ dan tinggi $200 \mathrm{~mm}$. Data yang digunakan mengacu pada jurnal berjudul "Experimental investigation of the performance of concrete columns strengthened with fiber reinforced concrete jacket” oleh Gholampour, A., dkk [1].

\subsection{Pemodelan dan Input Data ABAQUS}

Tahap ini dilakukan pemodelan dan input properti material pada program bantu ABAQUS. Program ABAQUS akan menganalisa perilaku material menggunakan metode elemen hingga. Secara garis besar, prosedur perhitungan analisa sebuah material atau struktur dengan menggunakan metode elemen hingga, yaitu :

a. Membagi struktur menjadi elemen hingga atau diskretisasi;

b. Menyusun properti material pada setiap material;

c. Menggabungkan elemen hingga dan formulasinya menjadi elemen utuh stuktur;

d. Memberikan beban sesuai rencana;

e. Menentukan kondisi batas struktur;

f. Menyesuaikan persamaan yang terbentuk (output dari analisa berupa displacement pada batas antar elemen);

g. Menghitung tegangan dan gaya dalam dari elemen-elemen (berdasarkan formulasi elemen material).

Pemodelan material benda uji yang sesuai dengan studi kasus pada program ABAQUS dapat dilihat pada Gambar 3. Bahan rujukan penelitian menggunakan kolom berbentuk silinder. Silinder terbagi menjadi dua bagian yaitu kolom inti yang berdiameter $100 \mathrm{~mm}$ dan bagian retrofit di luar kolom inti setebal $25 \mathrm{~mm}$ (Gambar 4). Bagian retrofit yaitu concrete jacketing yang terdiri dari campuran beton dengan komposisi tambahan polyethylene fibers sebanyak volume rasio yang berbeda-beda dan juga tulangan dengan spesifikasi yang sama. Tebal selimut tambahan setelah diberi perilaku concrete jacketing adalah $12.5 \mathrm{~mm}$.

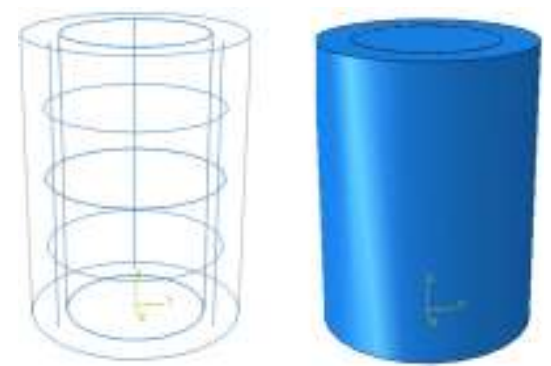

Gambar 3. Pemodelan Struktur Kolom Beton Bertulang pada ABAQUS

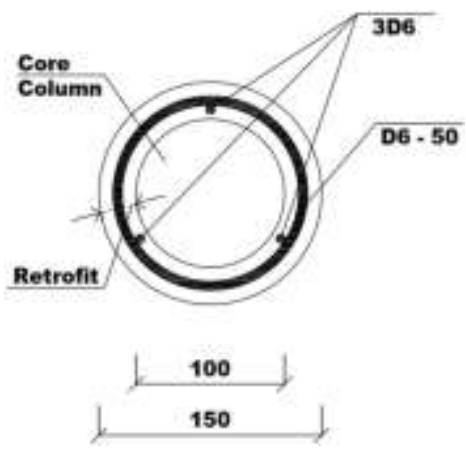

Gambar 4. Detail Struktur Kolom Beton Bertulang

\subsection{Perbandingan Hasil Analisis ABAQUS dengan Eksperimental}

Setelah hasil analisa ABAQUS didapatkan maka tahap selanjutnya adalah melakukan analisa dengan membandingkan perilaku material uji beton eksperimental dengan hasil analisa program bantu ABAQUS. Hasil uji eksperimental yang digunakan adalah hasil output eksperimental pada jurnal yang dipublikasikan berjudul "Experimental investigation of the performance of concrete columns strengthened with fiber reinforced concrete jacket" oleh Gholampour, A., dkk (2019). Dalam melakukan perbandingan, hasil uji eksperimental yang digunakan adalah gaya maksimum dan displacement pada material. 


\section{PEMBAHASAN}

\subsection{Perbandingan Hasil ABAQUS dengan Perhitungan Teoritis}

Perhitungan teoritis yang dimaksud ialah tegangan pada pemodelan sebgai validasi. Berikut adalah hasil perbandingan antara data hasil analisa dengan hasil perhitungan teoritis untuk masing-masing kasus :

Tabel 1. Validasi Model Beton Normal Menggunakan Persamaan Carreira \& Chu

\begin{tabular}{ccc} 
& ECC1 & ECC2 \\
\hline$\sigma$ & 60.7781 & 63.8497 \\
\hline$S 33$ & 38.8905 & 39.5346 \\
\hline rasio & 0.64 & 0.62 \\
\hline $\begin{array}{c}\text { Validasi } \\
(\%)\end{array}$ & 56.28 & 61.5032 \\
\hline
\end{tabular}

Tabel 2. Validasi Model Beton Normal Menggunakan Persamaan Alfarah, dkk

\begin{tabular}{ccc}
\hline & ECC1 & ECC2 \\
\hline$\sigma$ & 65.843 & 63.8497 \\
\hline$S 33$ & 73.28 & 71.295 \\
\hline rasio & 1.113 & 1.1166 \\
\hline $\begin{array}{c}\text { Validasi } \\
(\%)\end{array}$ & 10.149 & 10.4424 \\
\hline
\end{tabular}

\subsection{Perbandingan Hasil Analisa Program ABAQUS dengan Hasil Eksperimen}

Sub-bab ini dibahas hasil dari analisa program bantu ABAQUS dengan objek uji material beton bertulang retrofit, serta verifikasi hasil analisa dengan hasil eksperimen yang dilakukan di laboratorium. Perbandingan hasil eksperimen dengan menggunakan berbagai macam perbedaan perilaku retrofit pada beton dengan membandingkan displacement dan gaya yang didapat dari hasil penilitian Gholampour, dkk.

\subsubsection{Displacement dan Gaya Maksimum}

Gambar 5 menunjukkan perbandingan grafik hasil analisa program ABAQUS dengan hasil eksperimen. Dari perbandingan antara hasil simulasi dan eksperimen maka dapat diperoleh validasi bahwa hasil simulasi sesuai dan mendekati hasil eksperimen apabila ECC1 dan ECC2 menggunakan persamaan Alfarah, dkk. pada beton core concrete dan persamaan Zhou Jiajia, dkk untuk beton berkomposisi steel fiber (retrofit ECC1 dan ECC2). Perbandingan dalam bentuk nilai gaya maksimum dengan displacement pada gaya maksimum dapat dilihat pada Tabel 3.

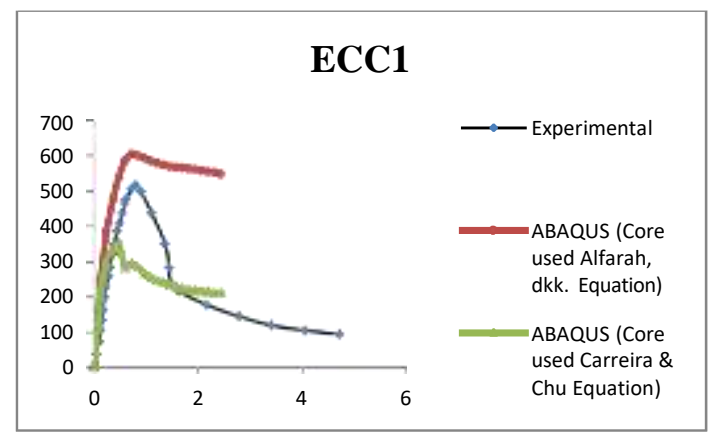

(a) Force vs discplacement beton ECC1

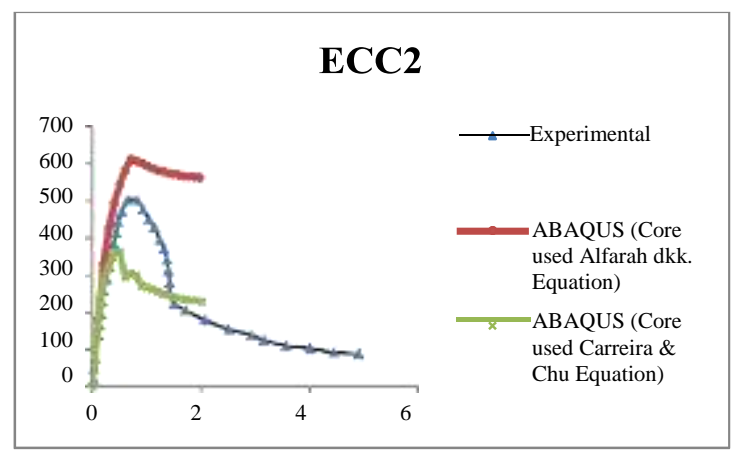

(b) Force vs discplacement beton ECC2

Gambar 5. Perbandingan hasil analisa ABAQUS force vs displacement dengan hasil eksperimental

Sehingga, hasil analisa ABAQUS force vs displacement yang menjadi pembanding dengan eksperimental adalah ECC1 dengan beton inti menggunakan persamaan Alfarah, dkk. dan beton retrofitnya menggunakan persamaan Zhou Jiajia, dkk., dan ECC2 dengan beton inti menggunakan persamaan Alfarah, dkk. dan beton retrofitnya menggunakan persamaan Zhou Jiajia, dkk. 
Tabel 3. Perbandingan Force vs Displacement

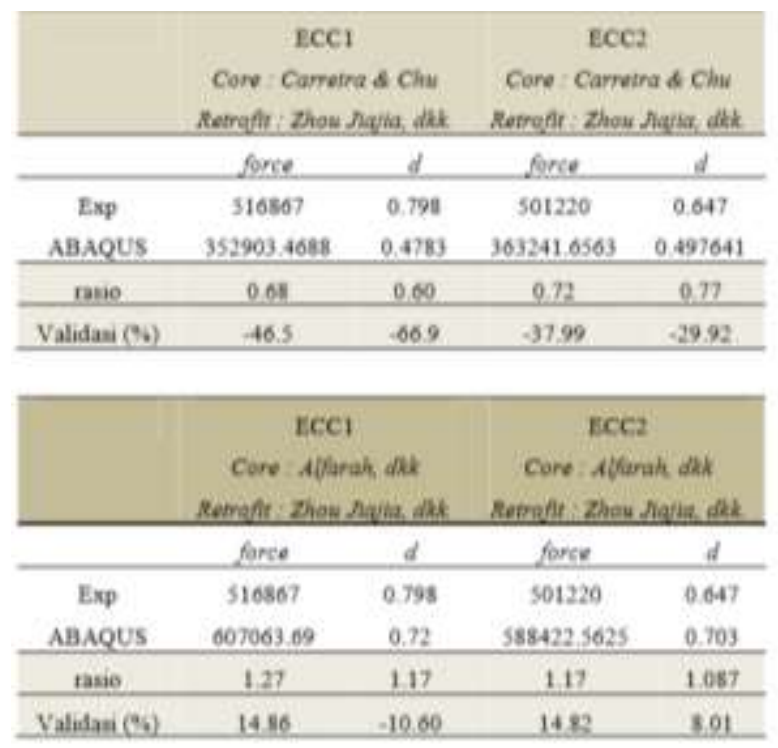

Hasil analisa tersebut diambil dikarenakan sifat yang lebih mendekati dan menggambarkan kedekatan perilaku yang dihasilkan. Hasil menunjukkan bahwa validasi saat menggunakan persamaan Alfarah, dkk. pada beton core concete yaitu ECC1 $17.53 \%$ dan ECC2 14.82\% (untuk gaya maksimumnya), ECC1 $3.19 \%$ dan ECC2 $8.01 \%$ (untuk perpindahannya). Sedangkan, apabila benda uji menggunakan persamaan Carreira \& Chu pada beton core concete menunjukkan hasil validasi yang sangat jauh nilainya yaitu ECC1 $35.2 \%$ dan ECC2 $37.99 \%$ (untuk gaya maksimumnya), ECC1 $29.21 \%$ dan ECC2 29.92\% (untuk perpindahannya). Maka dapat disimpulkan bahwa perhitungan kolom retrofit beton bertulang yang mendekati adalah dengan menggunakan persamaan Alfarah, dkk. untuk beton normal dan persamaan Zhou Jiajia, dkk untuk beton berkomposisi steel fiber. Grafik menunjukkan bahwa terdapat perbedaan antara ABAQUS dengan eksperimental dikarenakan terdapat galad pada analisa ABAQUS sendiri dan juga input pada $A B A Q U S$ merupakan hasil rata rata dari berbagai eksperimental sehingga dicapai persamaan tersebut. Di sisi lain, ada kemungkinan dikarenakan benda uji yang dikenakan adalah benda uji yang dianalisa memiliki dua sifat yang berbeda dalam satu kesatuannya menyebabkan galad pada analisa ABAQUS semakin tinggi. Sebagai pembanding antara hasil analisa ABAQUS dan eksperimental dapat dilihat pada Tabel 3.

\subsubsection{Damage Parameter}

Kerusakan pada beton hasil analisa pada ABAQUS dapat dikomparasikan dengan kerusakan beton hasil eksperimental. Perbandingan kerusakan menggunakan perbandingan antara hasil eksperimental dengan hasil hasil analisa ABAQUS yang mendekati yaitu dengan menggunakan persamaan Alfarah, dkk untuk beton biasa dan Zhou Jiajia, dkk untuk beton berkomposisi steel fiber. Gambar 4.2 menunjukkan perbandingan kerusakan hasil analisa program ABAQUS dengan hasil eksperimen. Dari perbandingan antara hasil simulasi dan eksperimen dapat disetujui bahwa hasil analisa pada ABAQUS mendekati keakuratan dalam memprediksi kerusakan saat beton mengalami pembebanan kuat tekan.

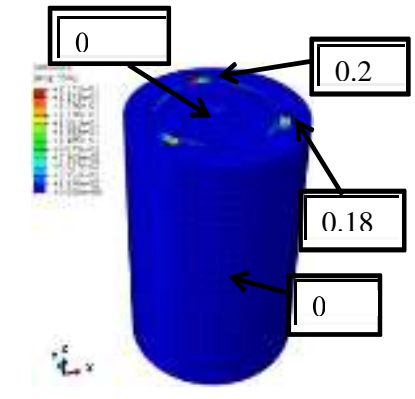

(a) ECC1

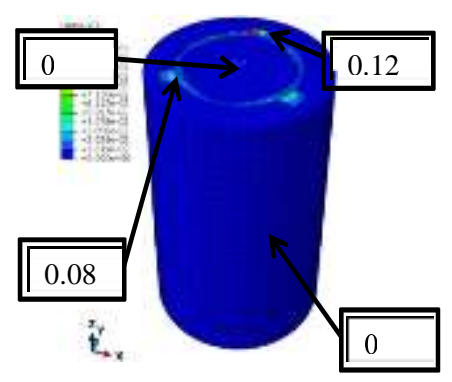

(b) ECC2

Gambar 6. Benda Uji Beton Setelah Pengujian 
Gambar 6 dapat dilihat bahwa beton mengalami kerusakan pada daerah antara beton inti (core concrete) dengan beton retrofit dan pada daerah luar beton retrofit. Pada ECC1 dan ECC2 terdapat nilai 0 pada tengah permukaan atas dan permukaan samping kolom.dapat diartikan bahwa tidak ada kerusakan atau retak pada bagian tersebut. Sementara semakin bertambah nilai kerusakannya semakin berwarna merah dan menandakan bahwa pola kerusakan seperti gambar tersebut. Terdapat nilai diantara beton inti dengan beton retrofit yaitu nilai kerusakan tertinggi pada ECC1 yaitu 0.237 dan pada ECC2 yaitu 0.1223 . Sementara gradasi warna pada gambar menunjukkan bahwa apabila terdapat biru muda sampai dengan merah maka pada daerah itulah beton mengalami kerusakan. Kerusakan tersebut terjadi saat beton telah mencapai masa ultimitnya.

\subsubsection{Kontur Tegangan}

Analisa kontur tegangan setiap spesimen pada hasil ABAQUS dapat dijelaskan secara rinci pada Gambar 7.
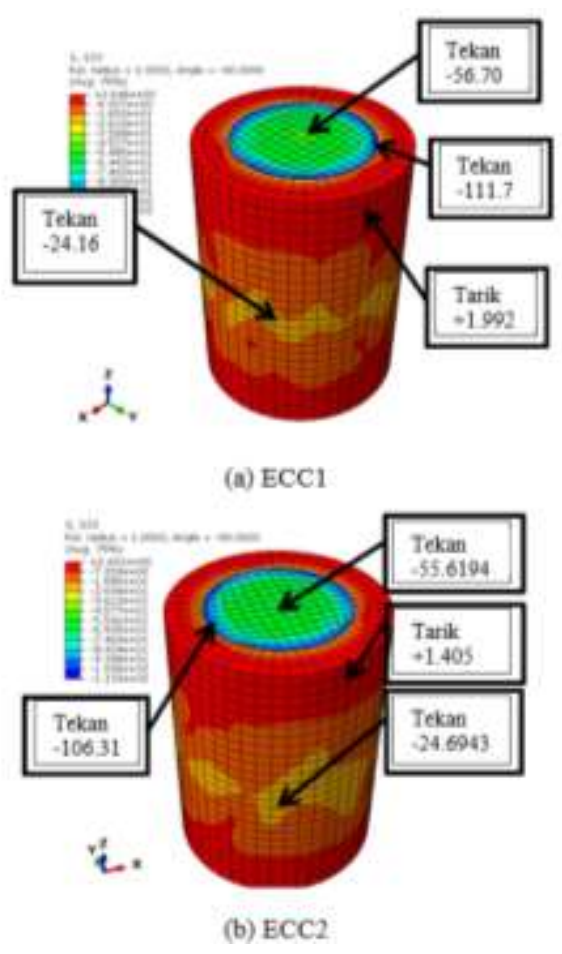

Gambar 7. Kontur Tegangan Benda Uji
Pada Gambar 7 dapat dilihat bahwa kontur pada beton ECC1, dan ECC2 tidak jauh berbeda. Pada bagian core concrete terjadi penambahan gradasi gaya tekan dari tengah hingga pinggir bagian core concrete. Penambahan gradasi nilai tersebut dapat dilihat bahwa pada ECC1 terjadi kenaikan dari -56.7 MPa hingga $-111.784 \mathrm{MPa}$, dan ECC2 terjadi kenaikan dari $-55.6194 \mathrm{MPa}$ hingga $-106.316 \mathrm{MPa}$. Sedangkan pada bagian luar retrofit terjadi sebagian luasan pada atas dan bawah mengalami gaya tarik dan pada bagian tengah mengalami gaya tekan. Pada bagian retrofit ECC1 sebesar +1.992 MPa, ECC2 sebesar $+1.405 \mathrm{MPa}$ dan gaya tekan ECC1 -24.1672 sebesar MPa, ECC2 sebesar -24.6943 MPa.

\section{KESIMPULAN DAN SARAN}

\subsection{Kesimpulan}

1. Skematisasi struktur model kolom retrofit pada program ABAQUS dapat disimpulkan sebagai berikut :

a. Pada pemodelan kolom beton dapat ditarik kesimpulan bahwa penggunaan persamaan perilaku tekan yang akurat untuk kasus menggunakan persamaan Alfarah, dkk. dan beton retrofit menggunakan persamaan Zhou Jiajia, dkk.

b. Pada pemodelan kolom beton penggunaan persamaan perilaku tarik yang akurat adalah untuk ECC1 dan ECC2 menggunakan persamaan CEB-FIB dan persamaan Ali \& Nehdi.

2. Hasil analisa ABAQUS tentang force vs displacement menunjukkan mendekati dengan kesamaan hasil uji eksperimental kolom beton retrofit (rasio force dan displacement ECC1 $14.86 \%$ dan $-10.60 \%$, dan ECC2 $14.82 \%$ dan $8.01 \%)$.

3. Hasil analisa perilaku material kolom retrofit akibat beban uniaksial yang dikenakan dengan menggunakan program ABAQUS setelah diaplikasikannya retrofit adalah sebagai berikut :

a. Hasil analisa kerusakan pada ABAQUS menunjukkan perilaku yang sesuai dan mendekati dengan keadaan pada spesimen kolom beton retrofit setelah pengujian.

b. Berdasarkan analisa tegangan menunjukkan bahwa terdapat gradasi 
kenaikan pada beton inti dimana puncak dari tegangan terdapat pada daerah pinggir beton inti dan pada daerah retrofit terbagi dua daerah yaitu tekan pada bagian tengah dan tarik pada sebagian kecil atas dan bawah kolom retrofit.

\subsection{Saran}

1. Pada pemodelan beton retrofit perlu diperhatikan perbandingan perbedaan ukuran mesh agar mengetahui perbandingan tingkat keakuratan ketika ukuran mesh diperkecil.

2. Data eksperimental sebagai pembanding dibutuhkan data yang diketahui oleh peneliti secara langsung agar mengetahui tingkat keakuratan persamaan yang digunakan saat input concrete damage plasticity.

\section{DAFTAR PUSTAKA}

[1] Gholampour, A., R. Hassanli, J. Mills, T. Vincent, dan M. Kunieda. "Experimental investigation of the performance of concrete columns strengthened with fiber reinforced concrete jacket". Construction and Building Materials 194 (2019): 51-61

[2] Carreira D. J., dan K. Chu. Stress-Strain Relationship for Plain Concrete in Compression. ACI Journal 82 (11), 1985: 797-
804

[3] Alfarah, B., Lopez-Almansa, F., dan Oller, S. New methodology for calculating damage variables evolution in Plastic Damage Model for RC structures. Engineering Structures 132, $2017: 70-86$

[4] Carreira D. J., dan K. Chu. Stress-Strain Relationship for Reinforced Concrete in Tension. ACI Journal 83 (3), $1986: 21-28$

[5] Wahalathantri B. L., D. P. Thamhiratnam, T. H. T. Chan, dan S. Fawzia. A Material Model for Flexural Crack Simulation in Reinforced Concrete Elements Using Abaqus. Infrastructure, Transport and Urban Development, $2011:$ 260-264

[6] Zhou, J., Pan, J., Leung, C., dan Asce, F. Mechanical Behabior of Fiber Reinforced Engineered Cementitious Composites in Uniaxial Compression. Materials Civil Engineering, 2014

[7] Ali, M. \& Nehdi, M. Experimental and Numerical Study of Engineered Cementitious Composite with Strain Recovery under Impact Loading. Applied Science, 2019 : 1-27

[8] CEB-FIB. CEB-FIB MODEL CODE 2010; Thomas Telford: London, UK, 2010 